\title{
Agreement in Walking Speed Measured Using Four Different Outcome Measures: 6-Meter Walk Test, 10-Meter Walk Test, 2-Minute Walk Test, and 6-Minute Walk Test
}

James Roush

A.T. Still University, jroush@atsu.edu

John D. Heick

Northern Arizona University, john.heick@nau.edu

Tanner Hawk

A.T. Still University, thawk@atsu.edu

Dillon Eurek

A.T. Still University, deurek@atsu.edu

Austin Wallis

A.T. Still University, awallis@atsu.edu

See next page for additional authors

Follow this and additional works at: https://nsuworks.nova.edu/ijahsp

Part of the Medicine and Health Sciences Commons

\section{Recommended Citation}

Roush J, Heick JD, Hawk T, Eurek D, Wallis A, Kiflu D. Agreement in Walking Speed Measured Using Four Different Outcome Measures: 6-Meter Walk Test, 10-Meter Walk Test, 2-Minute Walk Test, and 6-Minute Walk Test. The Internet Journal of Allied Health Sciences and Practice. 2021 Jan 01;19(2), Article 7.

This Manuscript is brought to you for free and open access by the College of Health Care Sciences at NSUWorks. It has been accepted for inclusion in Internet Journal of Allied Health Sciences and Practice by an authorized editor of NSUWorks. For more information, please contact nsuworks@nova.edu. 


\title{
Agreement in Walking Speed Measured Using Four Different Outcome Measures: 6-Meter Walk Test, 10-Meter Walk Test, 2-Minute Walk Test, and 6-Minute Walk Test
}

\begin{abstract}
Background: Walking speed is considered the sixth vital sign because it is a valid, reliable, and sensitive measure for assessing functional status in various populations. Purpose: The current study assessed agreement in walking speed using the 6-meter walk test, (6MWT) 10-meter walk test (10MWT), 2-minute walk test (2minWT), and 6-minute walk test (6minWT). We also determined differences in walking speed. Methods: Seventy-three healthy adults (44 females, 29 males; mean [SD] age=31.36 [10.33] years) participated. Lafayette Electronic timing devices measured walking speed for the 6MWT and 10MWT. Measuring wheels and stopwatches measured walking distance and speed for the 2minWT and 6minWT. Participants completed 1 trial, and all tests were administered simultaneously. Results: The intraclass correlation coefficient $(2,4)$ for the different measures of walking speed was excellent at $0.90(95 \%$ confidence intervals, 0.86-0.93). The correlation was 0.95 between 6MWT and 10MWT, 0.94 between $2 \mathrm{minWT}$ and $6 \mathrm{minWT}, 0.67$ between 6MWT and 2minWT, 0.63 between 10MWT and $2 \mathrm{minWT}$, and 0.59 between 10MWT and 6minWT (all $p<0.05$ ). No differences in walking speed were found between the four walking tests. Conclusion: Administration of any of the four walking tests provided reliable measurement of walking speed.
\end{abstract}

\author{
Author Bio(s) \\ James R. Roush, PT, PhD, AT,C, AT, is Professor Emeritus at A.T. Still University of Health Sciences in Mesa, \\ Arizona. \\ Dillon Eurek, PT, DPT, was a student at A.T. Still University of Health Sciences in Mesa, Arizona. \\ Tanner Hawk, PT, DPT, was a student at A.T. Still University of Health Sciences in Mesa, Arizona. \\ Daniel Kiflu, PT, DPT, was a student at A.T. Still University of Health Sciences in Mesa, Arizona. \\ Austin Wallis, PT, DPT, was a student at A.T. Still University of Health Sciences in Mesa, Arizona. \\ John D. Heick, PT, DPT, PhD, OCS, NCS, SCS, is an Associate Professor at Northern Arizona University in \\ Flagstaff, Arizona.
}

Acknowledgements

The authors would like to acknowledge Deborah Goggin, MA, for assistance in editing this paper.

Authors

James Roush, John D. Heick, Tanner Hawk, Dillon Eurek, Austin Wallis, and Daniel Kiflu 


\title{
IIJAHSP \\ The Internet Joumnal of Allied Health Sciences and Practice \\ Dedicated to allied health professional practice and education
}

Vol. 19 No. 2 ISSN 1540-580X

\section{Agreement in Walking Speed Measured Using Four Different Outcome Measures: 6-Meter Walk Test, 10-Meter Walk Test, 2-Minute Walk Test, and 6- Minute Walk Test}

\author{
James Rousch ${ }^{1}$ \\ John D. Heick² \\ Tanner HawK1 \\ Dillon Eurek ${ }^{1}$ \\ Daniel Kiflu ${ }^{1}$ \\ Austin Wallis ${ }^{1}$
}

1. A.T. Still University

2. Northern Arizona University

United States

\begin{abstract}
Background: Walking speed is considered the sixth vital sign because it is a valid, reliable, and sensitive measure for assessing functional status in various populations. Purpose: The current study assessed agreement in walking speed using the 6 -meter walk test, (6MWT) 10-meter walk test (10MWT), 2-minute walk test (2minWT), and 6-minute walk test (6minWT). We also determined differences in walking speed. Methods: Seventy-three healthy adults (44 females, 29 males; mean [SD] age=31.36 [10.33] years) participated. Lafayette Electronic timing devices measured walking speed for the 6MWT and 10MWT. Measuring wheels and stopwatches measured walking distance and speed for the $2 \mathrm{minWT}$ and 6 minWT. Participants completed 1 trial, and all tests were administered simultaneously. Results: The intraclass correlation coefficient $(2,4)$ for the different measures of walking speed was excellent at 0.90 (95\% confidence intervals, $0.86-0.93)$. The correlation was 0.95 between 6MWT and 10MWT, 0.94 between $2 \mathrm{minWT}$ and $6 \mathrm{minWT}, 0.67$ between 6MWT and $2 \mathrm{minWT}, 0.63$ between 10MWT and $2 \mathrm{minWT}$, and 0.59 between 10MWT and $6 \mathrm{minWT}$ (all $p<0.05$ ). No differences in walking speed were found between the four walking tests. Conclusion: Administration of any of the four walking tests provided reliable measurement of walking speed.
\end{abstract}

Keywords: walking speed, frailty, sixth vital sign, walking distance

*Corresponding author: John Heick, Northern Arizona University, P.O. Box 15105, Flagstaff, Arizona, 86011, email: John.Heick@nau.edu, phone: 928-523-8394, fax: 928-523-9289. 


\section{INTRODUCTION}

Walking ability is an important risk factor for morbidity and mortality in community-dwelling adults. ${ }^{1}$ Walking speed is considered a sixth vital sign because it is a valid, reliable, and sensitive measure for assessing functional status and health in a wide range of populations..$^{1,2}$ It is also a key component of evaluation in a variety of physical therapy practice settings and provides valuable information about function, quality of life, and how to improve the outcomes and care of patients ${ }^{2}$. As walking speed is an important indicator of a person's health status, it can be used to monitor changes during routine health care visits.

Walking speed has been assessed in a variety of patient populations, including older adults and those with stroke, Parkinson's disease, Alzheimer's disease, hip fracture, and knee osteoarthritis. ${ }^{3,4}$ A slow walking speed is one of the five criteria to describe frailty. ${ }^{5}$ Further, frailty is associated with physiological alterations, such as inflammation, glucose metabolism, and coagulation, and it can lead to abnormal neuromuscular function and a decrease in functional reserve of every organ system. 6,7 Normal walking speed is considered to be between $1.1 \mathrm{~m} / \mathrm{s}$ and $1.3 \mathrm{~m} / \mathrm{s}$ (between $2.6 \mathrm{mph}$ and $3.1 \mathrm{mph}$ ).3.4,8 $\mathrm{It}$ has been correlated with an increase in quality of life, and individuals who are community ambulators tend to have a significantly better quality of life than nonambulators. $^{8}$

Evidence supports the use of usual gait speed, time, or distance covered during walking performance tests, as predictors of mortality and potential cardiovascular events. ${ }^{9-14}$ In one study, a natural walking speed of $0.82 \mathrm{~m} / \mathrm{s}$ was most predictive of early mortality, and older men who walked faster than this cutoff speed were 1.23 times less likely to die than those who walked at slower speeds. ${ }^{15}$ Researchers have suggested that slower walking speed may be associated with greater severity of unhealthy conditions that are linked to mortality, such as cardiovascular disease and cancer. ${ }^{1}$ Therefore, walking speed is an important clinical measure to consider in multiple patient populations.

In multiple patient populations, walking speed can be assessed using a variety of tools, including the 6-meter walk test (6MWT), 10-meter walk test (10MWT), 2-minute walk test (2minWT), and 6-minute walk test (6minWT). These tools have high test-retest reliability and high interrater and intrarater reliability; however, each test has space requirements for completion and uses different measuring devices. For example, a hospital hallway may be used to measure the 6MWT, but an outpatient or home health practice setting may have limited space and level walking ground. Several studies have measured the 6MWT by asking participants to walk up and down a hallway of a specific length, which allows for the performance of the test in a setting with less area. 16,17 The design of these walking tests did not include any turns as this involves periods of deceleration when approaching a turn and then reacceleration after the turn thus affecting overall speed. This modification may be problematic as the total number of turns influences the walking speed and distance covered in 6 minutes. For patients with neurological disorders, some have recommended that the 6MWT be performed on a rectangular walkway. ${ }^{18-20}$ Others have investigated whether course length affects walking speed, but all of these studies have investigated clinical populations and not healthy individuals. ${ }^{21,22}$

The 10MWT, 2minWT, and 6minWT have shown strong correlations in a variety of diseases or impairments, ${ }^{3,4}$ which suggests agreement between measures since both types (length vs time) appear to provide similar information about walking ability. Although there is ample literature indicating a connection between walking speed and various diseases and impairments, little evidence exists supporting the correlation of walking speed in healthy adults with the various measurement tools. Therefore, the purpose of the current study was to assess agreement in walking speed as measured using the 6MWT, 10MWT, 2minWT, and $6 \mathrm{minWT}$. A secondary purpose was to determine differences in walking speed using these four different measures.

\section{MATERIALS AND METHODS \\ Study Design}

The current study used a quasi-experimental, repeated measures design. Outcome measures included time to complete the 6MWT and 10MWT and the distance covered during the $2 \mathrm{minWT}$ and $6 \mathrm{minWT}$. A sample size analysis indicated that 73 participants would be required for a power of at least 0.80 to identify an effect size $=0.7$; all $a=.01$, two-tailed.

\section{Procedures}

The A.T. Still University institutional review board approved the study (\#2018-014). All participants were informed of the benefits and risks of the study before signing an institutionally approved informed consent document to participate.

\section{Subjects}

Potential participants were recruited via flyers and word-of-mouth from a health sciences university. Participants were included in the study if they were aged between 21 and 65 years, had sufficient English proficiency to follow simple instructions for testing, and were able to ambulate independently for a minimum of 150 feet (45.72 meters) without the use of an assistive device. The 
lowa Level of Assistance Scale was used to define independence, so the participant had to be able to perform the activity safely without the supervision of another individual in the room. Exclusion criteria were lower extremity surgery within the past year, lowerextremity amputation within the past year, diagnosis of a neurologic condition, such as Parkinson's disease, or stroke with lower extremity involvement. Age, height in centimeters, and weight in kilograms of all participants were recorded, and body mass index (BMI) was calculated. Before and after the walking tests, heart rate and blood pressure were recorded using a standardized approach suggested by Frese et al. ${ }^{23}$

\section{Instrumentation}

An outside walking course was used in the current study. All four measures for walking speed were determined sequentially. For the 6 and 10 meter walking tests, the participant was instructed to walk at a self-selected speed, and the velocity was calculated as distance divided by time. ${ }^{24}$ For the 2 and 6 minute walking tests, the participant was instructed to walk at a comfortable speed over a flat and straight surface. $25-27$

The 6MWT is an activity-level domain measure that is highly correlated with functional status; it requires a flat and straight 10meter length walkway without turns. ${ }^{28,29}$ In the current study, the 6-meter course was mapped as 10 meters in length with a 2meter acceleration interval and a 6-meter testing interval. Two Lafayette Instrument Company Model 63501IR infrared sensors were connected to a Lafayette Instrument Company Model 54060 timing device. Masking tape was placed at the zero (0) meter point of the walking course. One sensor was placed at the 2-meter acceleration point. This sensor triggered the timing device to start recording. The other sensor was placed at the 6 -meter acceleration point and was set up to stop the timing device and record the time.

Like the 6MWT, the 10MWT is also an activity-level domain measure, but it requires a flat and straight 20-meter length walkway without turns. The first and last 5 meters are used to accelerate and decelerate, and only the middle 10 meters are recorded. In the current study, the 10-meter course was mapped as 20 meters in length with a 5-meter acceleration interval and a 10-meter testing interval. As above, two infrared sensors were connected to a timing device. Masking tape was placed at the zero (0) meter point of the walking course. One sensor was placed at the 5-meter acceleration point. This sensor triggered the timing device to start recording. The other sensor was placed at the 15-meter acceleration point and was set up to stop the timing device and record the time.

The $2 \mathrm{minWT}$ is a reliable and valid measure that reports the distance walked during a 2-minute walk. For the current study, at the end of the 15-meter portion of the course for the 10MWT, an investigator walked with the participant for two minutes. An Accusplit Pro 601X survivor stopwatch was used to measure the time. The investigator then used a Keson Metal Professional measuring wheel to measure the distance in meters.

The $6 \mathrm{minWT}$ is an activity-level domain test that measures the longest distance walked in 6 minutes. Like the $2 \mathrm{minWT}$, at the 15meter end of the walking course for the 10MWT, an investigator walked with the participant for six minutes. Time was recorded with a stopwatch, and the distance was measured in meters with a measuring wheel.

The outcome measure used in the current study was the lowa Level of Assistance Scale (ILAS). The ILAS grades the level of assistance according to the number of points of therapist physical contact to walk or perform tasks safely. The ILAS is a valid and reliable tool for patients with orthopedic conditions. ${ }^{30,31}$

\section{Data Collection}

Participants started the walking tests at the zero marcation on the walking course. They were instructed to begin walking at a comfortable walking speed through the mapped course. Data were recorded for all four tests sequentially, so participants were told to not stop until they had walked through the entire course. Each participant completed one trial. After the trial, the primary investigator recorded the time from the infrared sensor. Doctorate physical therapy students recorded the distance walked for the 2minWT and 6minWT with a Keson Metal Professional measuring wheel of each participant and calculated the walking speed in $\mathrm{cm} / \mathrm{sec}$. All testing was conducted when the outside temperature was between $70^{\circ} \mathrm{F}$ and $90^{\circ} \mathrm{F}\left(21^{\circ} \mathrm{C}\right.$ and $\left.32^{\circ} \mathrm{C}\right)$.

\section{Statistical Analyses}

Means and standard deviations (SD) were calculated for age, height, weight, BMI, walking time for the 2MWT and 10MWT, and walking distance for the $2 \mathrm{minWT}$ and $6 \mathrm{minWT}$. Walking speeds were then calculated as walking distance divided by walking time and are reported as $\mathrm{cm} / \mathrm{s}$. Pearson product-moment correlation coefficients were calculated to determine the relationship between the four different measures of walking speed. An intraclass correlation coefficient (ICC), model 2 (as the same rater was used for all four measures)(ICC), and a 95\% confidence interval (Cl) was calculated to determine the agreement between the measures of 
walking speed. The significance level was set at an a of 0.05 . If the correlations were considered high, Bland-Altman plots were used to observe the agreement in outcomes between the different measures of walking speed. Microsoft Excel (Redmond, WA) and SPSS statistical software version 23.0 (IBM, Chicago, IL) were used for data collection and analysis.

\section{RESULTS}

The demographic characteristics of the study participants are reported in the Table. Thirty male and 44 female graduate students from the health sciences university participated in the current study. Age ranged between 21 and 35 years; mean [SD] age $=31.36$ [10.33] years. Calculated walking speed for the four different measures of walking speed is reported in Figure 1. Because there was an overlap of the intervals for the four tests, we deduced there were no differences in walking speed between the two sexes and the four different measures. The lowa Level of Assistance score was zero for all participants as no assistance was needed for the participants.

Table. Demographic characteristics and walking test outcomes of study participants

\begin{tabular}{lll}
\hline Variable & Mean $(\mathbf{S D})$ & \\
\cline { 2 - 3 } & Male $(\mathbf{n}=\mathbf{3 0})$ & Female $(\mathbf{n}=\mathbf{4 4})$ \\
\hline Age, $\mathrm{y}$ & $30.83(7.32)$ & $32.82(11.85)$ \\
Height, $\mathrm{cm}$ & $178.79(7.59)$ & $165.56(7.44)$ \\
Weight, $\mathrm{kg}$ & $86.94(20.10)$ & $66.92(11.60)$ \\
Body mass index & $27.02(4.42)$ & $24.44(4.13)$ \\
6-Meter walk test time, $\mathrm{s}$ & $3.83(0.42)$ & $4.12(0.62)$ \\
10-Meter walk test time, $\mathrm{s}$ & $6.61(0.68)$ & $7.05(0.94)$ \\
2-Minute walk test distance, $\mathrm{m}$ & $180.81(13.41)$ & $173.47(17.28)$ \\
6-Minute walk test distance, $\mathrm{m}$ & $541.04(36.84)$ & $525.17(44.46)$ \\
\hline
\end{tabular}

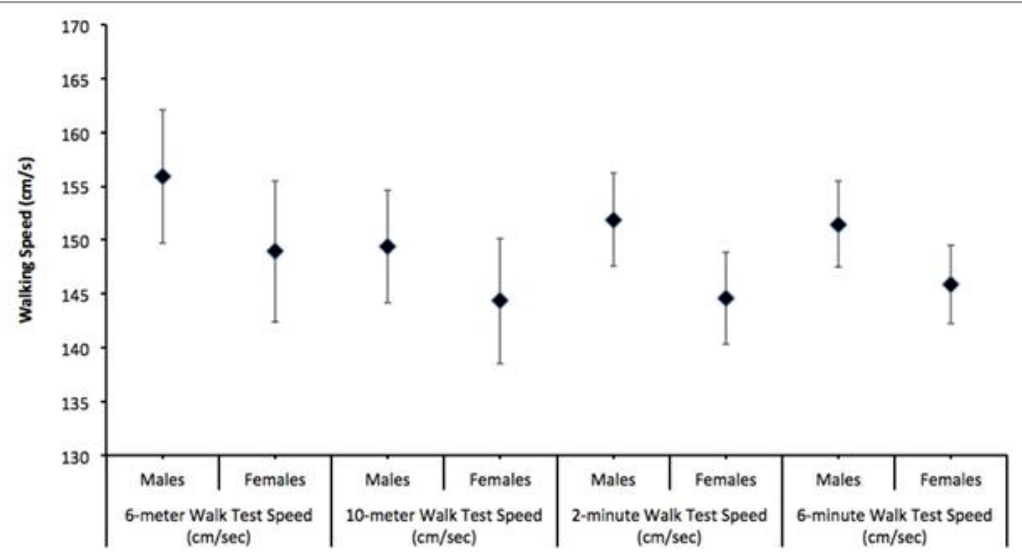

Figure 1. Means and $95 \%$ confidence interval for the four measures of walking speed.

The calculated ICC $(2,4)$ to determine agreement in walking speed for the four different measures was $0.90(95 \% \mathrm{Cl}, 0.86-0.93)$ and was classified as substantial using Shrout's criteria. The correlation matrix for the relationships of the four measures is presented in Figure 2. All correlations were significant (all $p<0.05)$. The relationship between the 6MWT and 10MWT was quite high (Pearson $r=0.94 ; 95 \% \mathrm{Cl}, 0.93-0.95$ ). The relationship between the $2 \mathrm{minWT}$ and $6 \mathrm{minWT}$ ) was also quite high (Pearson $r=$ $0.95 ; 95 \% \mathrm{Cl}, 0.94-0.96)$.

Because the correlation coefficients between the two types of walking speed measures were high, Bland-Altman plots were created (Figures 3 and 4). For both plots, the bias lines were close to zero, and the scatter points appeared random. The range between the $\mathrm{SD}( \pm 1.96 \mathrm{SD})$ was narrow, suggesting any bias between the four measures was probably not clinically important. 


\begin{tabular}{|c|c|c|c|c|}
\hline & $\begin{array}{c}\text { 6-meter Walk Test } \\
\text { Speed (cm/sec) }\end{array}$ & $\begin{array}{c}\text { 10-meter Walk Test } \\
\text { Speed (cm/sec) }\end{array}$ & $\begin{array}{c}\text { 2-minute Walk Test } \\
\text { Speed (cm/sec) }\end{array}$ & $\begin{array}{c}\text { 6-minute Walk Test } \\
\text { Speed (cm/sec) }\end{array}$ \\
\hline $\begin{array}{c}\text { 6-meter Walk Test } \\
\text { Speed (cm/sec) }\end{array}$ & 1.00 & $.94 *$ & $.67 *$ & $.63 *$ \\
\hline $\begin{array}{c}\text { 10-meter Walk Test } \\
\text { Speed (cm/sec) }\end{array}$ & 1.00 & $.63 *$ & $.59 *$ \\
\hline $\begin{array}{c}\text { 2-minute Walk Test } \\
\text { Speed (cm/sec) }\end{array}$ & & 1.00 & $.95 *$ \\
\hline $\begin{array}{c}\text { 6-minute Walk Test } \\
\text { Speed (cm/sec) }\end{array}$ & & & 1.00 \\
\hline
\end{tabular}

Figure 2. Correlation matrix for the four different walking speed tests ${ }^{*}$ Denotes significance at an alpha levelof 0.5

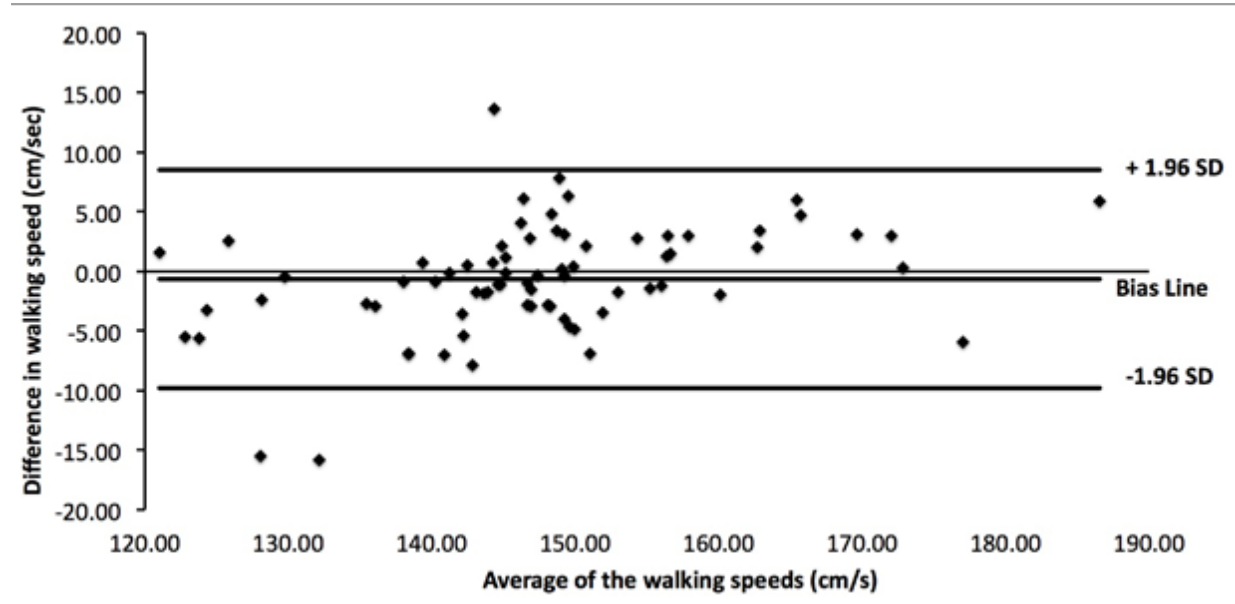

Figure 3: Bland Altman Plot of 2-minute Walk Test versus 6 -minute Walk Test

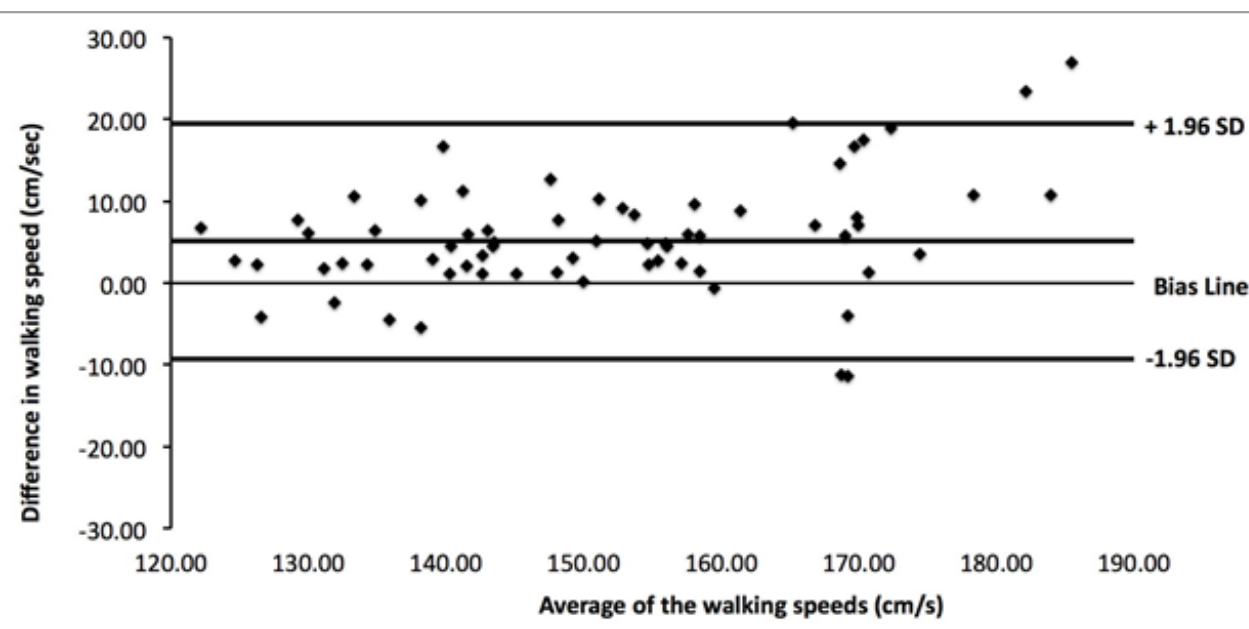

Figure 4. Bland Altman Plot of 6-meter Walk Test with 10-meter Walk Test 


\section{DISCUSSION}

In the current study, no differences were found in walking speed between the four different tests (Figure 2). This finding suggests that any of the four tests could be used in practice settings that have limited space to measure walking speed. Because walking speed is considered the sixth vital sign, our results are important because they provide clinicians flexibility when choosing a test that does not need to be adapted or modified to fit the clinician's practice setting. ${ }^{1,2}$ For example, if a clinic has limited space that prevents the patient from being able to walk on a flat, straight walkway without turns for 10 meters, 6 meters, for 6 minutes or for 2 minutes then an appropriate walking test would need to be used for that practice setting meaning most outpatient clinics would require the patient to be tested outside. The equipment needed for measuring walking speed between the four measures is minimal and has utility in multiple settings.

For example, the $6 \mathrm{minWT}$ can be performed on a treadmill with distance measured in meters. In the current study, infrared sensors were used to measure precise walking speed for our comparisons, but this equipment is not necessary for a clinical setting when testing 6-meter or 10-meter walking speed. Clinically, both of these tests are measured by a stopwatch and although not as precise as an infrared sensor, a stopwatch is inexpensive and an accurate measure for walking speed. In the current study, a Keson Metal Professional measuring wheel was used to precisely measure the distance walked for the $2 \mathrm{minWT}$ and $6 \mathrm{minWT}$. This inexpensive device is ideal for clinicians who want to measure the precise distance walked. A recent study concluded the use of a measuring wheel reflects physical performance more accurately because it measures turns that are incorporated into these measures more accurately. 32 In another study, researchers suggested that turns require adjustments in speed and increase the complexity of the test, making it harder to standardize over multiple assessment sessions and between patients; therefore, any improvement in the measurement of turns is beneficial. ${ }^{2}$ The authors of the current study mention turns because many of the clinical settings that use these walking speed tests modify these tests and include multiple turns during the walking test.

Each of the four measures used to assess walking speed in the current study has ample evidence to support their use. However, one study reported few physical therapists measure the walking speed of patients. ${ }^{22,33}$ Salbach et al noted that $32 \%-44 \%$ of physical therapists reported testing walking speed even though it is considered vital information. ${ }^{34}$ Two other studies reported $11 \%-44 \%$ of physical therapists measured walking distance. ${ }^{35,36}$ Perhaps this lack of assessment of walking speed or walking distance results from time constraints of physical therapists across clinical settings or the medical complexity of patients with multiple comorbidities. Others have suggested that muscle weakness, gait inefficiency, or poor endurance may contribute to the lack of assessment of walking speed or distance tests. ${ }^{37,38}$

Because the $2 \mathrm{minWT}$ and $6 \mathrm{minWT}$ require the patient to walk a distance for the specified time, these tests may be inappropriate for those patients who may be unable to complete the required distance. Therefore, we recommend that this potential limitation should be considered before testing and that vital signs should be taken before testing any of the four measures to ensure patient safety. Also the $6 \mathrm{minWT}$ may be too difficult for specific populations of patients. Authors suggest older adults are not able to walk 400 meters during the $6 \mathrm{minWT} .{ }^{29,39}$ Steffen et al specifically noted that a walked distance of fewer than 300 meters in 6 minutes predicted an increased likelihood of death in patients with left ventricular dysfunction. ${ }^{40}$ Based on the results of the current study, the $2 \mathrm{minWT}$ or the 10MWT may be better suited to estimate walking speed for patients unable to tolerate longer distances such as the 6minWT, and it may be a more efficient way of measuring walking speed for the therapist limited by time constraints. However, each clinician needs to decide which test and measurement method best suit the patient's presentation and the patient's restrictions or impairments.

For example, in a patient with an endurance limitation, the $2 \mathrm{minWT}$ may be ideal, but if the clinician wants to measure endurance, the 6minWT is better. In general, clinicians need tests that are efficient as well as reliable and valid, and walking speed is an important measure that can be quickly assessed in multiple practice settings Middleton et al provide an excellent resource of minimal detectable change differences for walking speed and walking distance across multiple populations. ${ }^{2}$

In the current study, no differences between sexes were found in walking speed across the four different tests. This finding contradicts other studies investigating specific walking speed tests. In a systematic review, Salbach et al reported differences between sexes and age for the 6minWT. ${ }^{34}$ The mean self-selected speed of males and females for that test were grouped by decade, and males generally reported a higher walking speed than females for all age ranges (20-30 years up to 70-79 years). ${ }^{34}$ The authors also noted differences in walking speed for sex-specific age decades across four countries and for sex differences in walking speed across the United States. ${ }^{34}$ However, no evidence of differences or similarities in sex across the other three measures were found in that study.

When determining which of the four measures of walking speed should be used, the clinician should consider which test is best for the specific patient population and how much space is available to perform the test. Amatachaya et al suggest that one limitation 
of assessing walking speed is related to the available area and depends on the facility where the test occurs. ${ }^{3}$ Further, the number of turns influences walking speed and distance, especially for patients with neurological disorders. Multiple studies have recommended that, when using the $6 \mathrm{minWT}$, the setting needs to have a rectangular walkway that is clear of obstacles to limit the influence of the increased number of turns..$^{18-20}$ Although there will be turns in tests that use a 4-meter to 10-meter walkway, a rectangular walkway allows the patient to only have to turn $90^{\circ}$ rather than $180^{\circ}$. Because this modification of the walking speed test may change results, it requires more investigation in future studies. Researchers have also suggested that instruction and encouragement during gait speed tests should be considered and rigorously standardized so that knowledge of performance and results do not influence the patient's gait speed. ${ }^{20}$ For instance, if clinicians want the patient to do well or improve over time, they may unconsciously provide the patient with a feedback on performance during the test. The current study did not provide knowledge of performance to participants, and we agree with the previous recommendation of rigorously standardizing each walking speed test.

\section{Limitations}

The current study had several limitations. All four measures of walking speed were assessed in one continuous trial, and all testing was done sequentially. There were several reasons why the study was performed this way. Since the study was conducted in a warmer climate, we were concerned about the influence of increasing temperature, so we determined that all participants needed to be tested in the morning. Testing was conducted when the outside temperature was between $70^{\circ} \mathrm{F}$ and $90^{\circ} \mathrm{F}\left(21^{\circ} \mathrm{C}\right.$ and $\left.32^{\circ} \mathrm{C}\right)$. Although all participants were acclimated to this climate, the temperature may have influenced their performance. Testing was completed outside over even ground, but this environment may be difficult to replicate for clinicians who test patients in different clinical settings, such as a busy hospital hallway or inside or outside of a patient's home. Because the current study investigated healthy participants, our results may not apply to all patient populations. Therefore, clinicians need to select the most appropriate test and measurement method that matches the patient population being tested. Given the results of the current study, we encourage more physical therapists to assess walking speed than the $11 \%-44 \%$ who reported doing $50.35,36$ We especially encourage increased use of this assessment because walking speed is well established in the literature and is considered the sixth vital sign..$^{1,2}$

\section{CONCLUSIONS}

The results of the current study suggested that the administration of any of the four walking tests would provide a reliable measurement of walking speed. These findings are important and should be considered when clinicians determine the best test to assess walking speed given the patient's condition, the facility's setting, and the equipment needed for measuring gait speed. Walking speed for all individuals is important. For example, the amount of time it takes an individual to cross a street involves the parameter of walking speed. Whether the patient has impairments such as an incomplete spinal cord injury, multiple sclerosis, stroke, Parkinson's disease, a total hip replacement, a total knee replacement, an ACL injury, low back pain, or other lower extremity injury; the time to cross a street is set between 3 to 6 miles/hour by the Department of Transportation. The amount of time to cross the street is not set to any specific patient population other than to the general population. Signals at crosswalks are not changed to any specific population. The authors of the current study designed this study for the general population. The main concern of the authors of the current study is how to address the hesitation by clinicians in measuring walking speed for their patients. At this time, the five vital signs measured by clinicians are blood pressure, heart rate, respiratory rate, temperature, and pain. The authors of the current study suggest that clinicians consider gathering some measure of walking speed, whether formally (using a stopwatch and a specific distance) or informally (through observation) on patients seen for physical therapy. For example, if a 30-year-old patient walks at a slow speed during a visit to his/her physician, the physician should note it and make an appropriate referral. Not noting this impairment and not making the appropriate referral could be considered malpractice.

\section{ACKNOWLEDGMENTS}

The authors would like to acknowledge Deborah Goggins, MA, for assistance in editing this paper.

\section{DECLARATION OF INTEREST}

The authors report no conflict of interest. The authors did not receive funding for this work. 


\section{REFERENCES}

1. Franklin $B A$, Brinks $J$, Sacks $R$, et al. Reduced walking speed and distance as harbingers of the approaching grim reaper. Am J Cardiol. 2015;116(2):313-317.

2. Middleton A, Fritz SL, Lusardi M. Walking speed: the functional vital sign. J Aging Phys Act. 2015;23(2):314-322.

3. Amatachaya S, Naewla S, Srisim K, et al. Concurrent validity of the 10-meter walk test as compared with the 6-minute walk test in patients with spinal cord injury at various levels of ability. Spinal Cord. 2014;52(4):333-336.

4. Eden MM, Tompkins J, Verheijde JL. Reliability and a correlational analysis of the 6MWT, ten-meter walk test, thirty second sit to stand, and the linear analog scale of function in patients with head and neck cancer. Physiother Theory Pract. 2018;34(3):202-211.

5. Fried LP, Tangen CM, Walston J, et al. Frailty in older adults: evidence for a phenotype. J Gerontol A Biol Sci Med Sci. 2001;56(3):M146-156.

6. Walston J, Hadley EC, Ferrucci L, et al. Research agenda for frailty in older adults: toward a better understanding of physiology and etiology: summary from the American Geriatrics Society/National Institute on Aging Research Conference on Frailty in Older Adults. J Am Geriatr Soc. 2006;54(6):991-1001.

7. Kamiya K, Adachi T, Kono Y, et al. The 6-Minute Walk Test: DIFFERENCE IN EXPLANATORY VARIABLES FOR PERFORMANCE BY COMMUNITY-DWELLING OLDER ADULTS AND PATIENTS HOSPITALIZED FOR CARDIAC DISEASE. J Cardiopulm Rehabil Prev. 2019;39(5):E8-E13.

8. Khanittanuphong P, Tipchatyotin S. Correlation of the gait speed with the quality of life and the quality of life classified according to speed-based community ambulation in Thai stroke survivors. NeuroRehabilitation. 2017;41(1):135-141.

9. Cesari M, Kritchevsky SB, Penninx BW, et al. Prognostic value of usual gait speed in well-functioning older people-results from the Health, Aging and Body Composition Study. J Am Geriatr Soc. 2005;53(10):1675-1680.

10. Jefferis BJ, Whincup PH, Papacosta O, et al. Protective effect of time spent walking on risk of stroke in older men. Stroke. 2014;45(1):194-199.

11. Lo AX, Donnelly JP, McGwin G, Jr., et al. Impact of gait speed and instrumental activities of daily living on all-cause mortality in adults $>/=65$ years with heart failure. Am J Cardiol. 2015;115(6):797-801.

12. Manson JE, Greenland P, LaCroix AZ, et al. Walking compared with vigorous exercise for the prevention of cardiovascular events in women. N Engl J Med. 2002;347(10):716-725.

13. Studenski S, Perera S, Patel K, et al. Gait speed and survival in older adults. Jama. 2011;305(1):50-58.

14. Yazdanyar A, Aziz MM, Enright PL, et al. Association Between 6-Minute Walk Test and All-Cause Mortality, Coronary Heart Disease-Specific Mortality, and Incident Coronary Heart Disease. J Aging Health. 2014;26(4):583-599.

15. Stanaway FF, Gnjidic D, Blyth FM, et al. How fast does the Grim Reaper walk? Receiver operating characteristics curve analysis in healthy men aged 70 and over. BMJ. 2011;343:d7679.

16. Dean CM, Richards CL, Malouin F. Walking speed over 10 metres overestimates locomotor capacity after stroke. Clin Rehabil. 2001;15(4):415-421.

17. Kim CM, Eng JJ, Whittaker MW. Level walking and ambulatory capacity in persons with incomplete spinal cord injury: relationship with muscle strength. Spinal Cord. 2004;42(3):156-162.

18. Jackson $\mathrm{AB}$, Carnel $\mathrm{CT}$, Ditunno JF, et al. Outcome measures for gait and ambulation in the spinal cord injury population. J Spinal Cord Med. 2008;31(5):487-499.

19. van Hedel HJ, Dietz V, Curt A. Assessment of walking speed and distance in subjects with an incomplete spinal cord injury. Neurorehabil Neural Repair. 2007;21(4):295-301.

20. van Hedel HJ, Wirz M, Dietz V. Standardized assessment of walking capacity after spinal cord injury: the European network approach. Neurol Res. 2008;30(1):61-73.

21. Peters DM, Fritz SL, Krotish DE. Assessing the reliability and validity of a shorter walk test compared with the 10-Meter Walk Test for measurements of gait speed in healthy, older adults. J Geriatr Phys Ther. 2013;36(1):24-30.

22. Salbach NM, Mayo NE, Higgins $\mathrm{J}$, et al. Responsiveness and predictability of gait speed and other disability measures in acute stroke. Arch Phys Med Rehabil. 2001;82(9):1204-1212.

23. Frese EM, Fick A, Sadowsky HS. Blood pressure measurement guidelines for physical therapists. Cardiopulm Phys Ther J. 2011;22(2):5-12.

24. Bushnell C, Bettger JP, Cockroft KM, et al. Chronic Stroke Outcome Measures for Motor Function Intervention Trials: Expert Panel Recommendations. Circ Cardiovasc Qual Outcomes. 2015;8(6 Suppl 3):S163-169.

25. Brooks D, Parsons J, Hunter JP, et al. The 2-minute walk test as a measure of functional improvement in persons with lower limb amputation. Arch Phys Med Rehabil. 2001;82(10):1478-1483.

26. Connelly DM, Thomas BK, Cliffe SJ, et al. Clinical utility of the 2-minute walk test for older adults living in long-term care. Physiother Can. 2009;61(2):78-87. 
27. Resnik L, Borgia M. Reliability of outcome measures for people with lower-limb amputations: distinguishing true change from statistical error. Phys Ther. 2011;91(4):555-565.

28. Tan DM, McGinley JL, Danoudis ME, et al. Freezing of gait and activity limitations in people with Parkinson's disease. Arch Phys Med Rehabil. 2011;92(7):1159-1165.

29. Thomas DR, Marren $\mathrm{K}$, Banks W, et al. Do objective measurements of physical function in ambulatory nursing home women improve assessment of functional status? J Am Med Dir Assoc. 2007;8(7):469-476.

30. Shields RK, Enloe LJ, Evans RE, et al. Reliability, validity, and responsiveness of functional tests in patients with total joint replacement. Phys Ther. 1995;75(3):169-176; discussion 176-169.

31. Lynch EA, Hillier SL, Stiller K, et al. Sensory retraining of the lower limb after acute stroke: a randomized controlled pilot trial. Arch Phys Med Rehabil. 2007;88(9):1101-1107.

32. Rauchenzauner M, Schneider J, Colleselli V, et al. Comparing modalities of conducting the six-minute walk test in healthy children and adolescents. Minerva Pediatr. 2019;71(3):229-234.

33. Latham NK, Jette DU, Slavin M, et al. Physical therapy during stroke rehabilitation for people with different walking abilities. Arch Phys Med Rehabil. 2005;86(12 Suppl 2):S41-S50.

34. Salbach NM, Guilcher SJ, Jaglal SB. Physical therapists' perceptions and use of standardized assessments of walking ability post-stroke. J Rehabil Med. 2011;43(6):543-549.

35. Stokes EK, O'Neill D. Use of outcome measures in physiotherapy practice in ireland from 1998 to 2003 and comparison to canadian trends. Physiother Can. 2008;60(2):109-116.

36. Van Peppen RP, Maissan FJ, Van Genderen FR, et al. Outcome measures in physiotherapy management of patients with stroke: a survey into self-reported use, and barriers to and facilitators for use. Physiother Res Int. 2008;13(4):255270.

37. Brooks D, Davis AM, Naglie G. The feasibility of six-minute and two-minute walk tests in in-patient geriatric rehabilitation. Can J Aging. 2007;26(2):159-162.

38. Pin TW. Psychometric properties of 2-minute walk test: a systematic review. Arch Phys Med Rehabil. 2014;95(9):17591775.

39. Chang M, Cohen-Mansfield J, Ferrucci L, et al. Incidence of loss of ability to walk 400 meters in a functionally limited older population. J Am Geriatr Soc. 2004;52(12):2094-2098.

40. Steffen TM, Hacker TA, Mollinger L. Age- and gender-related test performance in community-dwelling elderly people: Six-Minute Walk Test, Berg Balance Scale, Timed Up \& Go Test, and gait speeds. Phys Ther. 2002;82(2):128-137. 